\title{
Atomic Force Microscopy Applications to the Next Generation Lithium-ion Batteries
}

\author{
Ji Hyun Lee, Sang Hyuk Gong, Hyeong Woo Kim, Hyung-Seok Kim ${ }^{\dagger}$
}

Korea Institute of Science and Technology, Seoul 02792, Korea

\section{차세대 리튬이온이차전지 연구에서의 원자력 현미경 활용}

\author{
이지현, 공상혁, 김형우, 김형석 \\ 한국과학기술연구원
}

(Received December 11, 2019; Accepted December 16, 2019)

\begin{abstract}
s
Recently, demands for lithium-ion batteries (LIB) in various fields are increasing. In particular, understanding of the reaction mechanism occurring at the electrode-electrolyte surface/interface is significant for the development of advanced LBBs. Meanwhile, research and development of LIBs highly requires a new specific characterization approach. For example, atomic force microscopy (AFM) has been utilized to the LIB research field for various purposes such as investigation of topography, electrochemical reactions, ion transport phenomena, and measurement of surface potential at high resolution. Advances in the AFM analysis have made it possible to inspect various material properties such as surface friction and Young's modulus. Therefore, this technique is expected to be a powerful method in the LIB research field. Here, we review and discuss ways to apply AFM to LIB studies
\end{abstract}

Key words : Atomic force microscopy, Lithium-ion batteries, Solid electrolyte interphase

\section{1. 서론}

리튬 이온 배터리(LIB)는 1980년 John Bannister Goodenough에 의해 발명되고 1991년 Sony에 의해 상 용화 된 이후 지금까지 계속해서 전세계의 주목을 받고 연구되고 있다. ${ }^{1)} \mathrm{LIB}$ 는 현재 휴대용 전기 장치에 쓰이는
소형에너지 저장장치에서부터 전기 자동차 및 중대형에 너지저장시스템(ESS)에 적용되는 중대형 에너지 저장 장 치에 이르기까지 널리 적용되고 있다. 특히, 블룸버그 신 에너지 파이낸스 $(\mathrm{BNEF})$ 는 전기 자동차 생산에 투입되는 LIB의 연간 수요가 2025년과 2030년 각각 $408 \mathrm{GWh}$ $1293 \mathrm{GWh}$ 에 도달 할 것으로 예측했다. ${ }^{2}$ 
이처럼 LIB 관련 시장은 빠르게 성장하고 있는 것에 비 해 소재 개발은 다소 정체되어 있다. LIB의 구성은 양극 재, 음극재, 전해질, 분리막 등의 핵심소재로 이루어져 있으며, 고에너지밀도, 장수명, 가격 및 안전성 등은 차 세대 LIB개발에 있어 핵심 요구사항이다. 이러한 특성들 을 만족시키기 위해 지난 30 년동안 $\mathrm{LiCoO}_{2}, \mathrm{LiMnO}_{4}$ 및 $\mathrm{LiFeO}_{4}$ 를 포함한 여러 유형의 양극 소재가 개발되어 상 용화되었다. ${ }^{3)}$ 음극 소재의 경우 탄소 계 물질인 흑연이 개발되어 상용화 되어있고 실리콘과 리튬 금속 등 다양한 유형의 물질이 새로운 음극으로 제안되었지만 이러한 새 로운 음극은 아직 까지 상용화에 이르기에는 안전성, 성 능 및 신뢰성이 크게 못 미치는 실정이다. ${ }^{4)}$ 한편, 더 향상 된 성능의 LIB 소재 개발을 위해 전극 소재의 특성 및 반 응 메커니즘, 특히 전극-전해질 표면에서 일어나는 반응 의 명확한 이해를 위해 다양한 분석법이 개발 및 도입되 고있다. ${ }^{5)}$

지난 몇 년 동안, $\mathrm{LIB}$ 소재의 특성을 연구하기 위해 주 사 전자 현미경(SEM), 투과 전자 현미경(TEM), 투과 $\mathrm{X}$-선 현미경(TXRM), 원자 힘 현미경(AFM) 및 중성자 회절 등의 분석법들이 이용되어 왔다. ${ }^{6)}$ 위 분석법들 중 $\mathrm{AFM}$ 은 수 나노미터(nm)의 공간분해능으로 LIB소재의 기계적 및 전기화학적 특성 분석이 가능하다는 장점을 갖 고 있다. ${ }^{7)}$ 예를 들어서, $\mathrm{AFM}$ 의 다양한 측정 모드를 통해 충전 방전 과정 동안 전극의 지형 변화를 실시간으로 볼 수 있고 동시에 전기화학반응, 전류 분포, 표면 전위, 리 튬 이온 전달 등 표면 특성을 고해상도로 조사 할 수 있 다. ${ }^{8)}$ 본 지면에서는 다양한 측정 모드의AFM의 작동원리 에 대해 간단히 설명하고 $\mathrm{AFM}$ 의 다양한 측정기술들을 이용한 LIB연구의 최신 동향과 앞으로의 연구 방향에 대 해 논하려고 한다.

\section{2. 본론}

\subsection{AFM의 원리}

스캐닝 프로브 현미경(SPM)의 한 종류인 $\mathrm{AFM}$ 은 1985 년에 국소 부위 특성을 측정하기 위해 발명되었다.

$\mathrm{AFM}$ 의 기본 작동원리는 그림1에서 볼 수 있듯이,

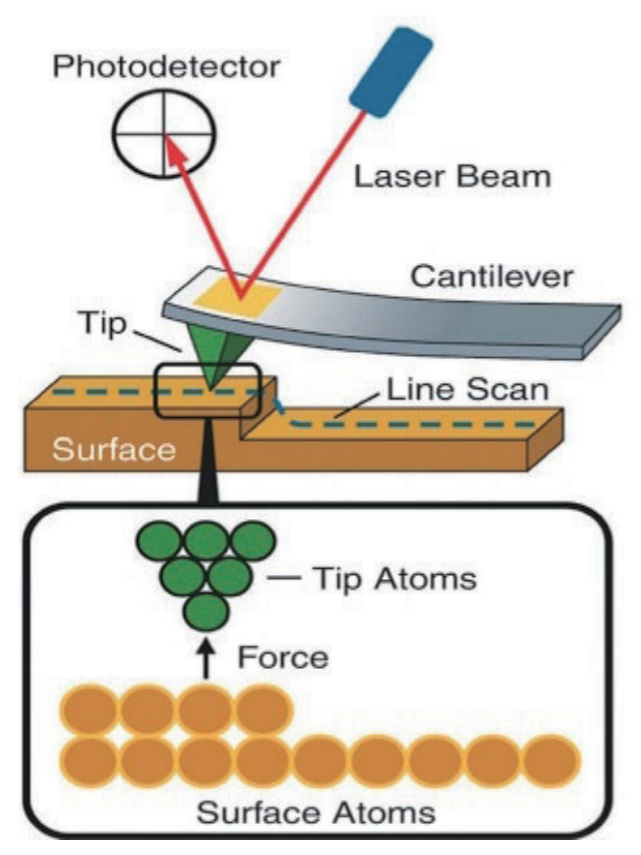

그림 1. AFM의 기본 원리 개략도.

$\mathrm{AFM}$ 은 캔틸레버(cantilever)에 장착 된 매우 날카로운 팁을 사용하여 샘플 표면을 스캔하며 프로브(probe) 원 자와 시료 사이의 힘을 측정한다. $\mathrm{AFM}$ 에서는 일반적으 로 접촉 모드(팁이 시료에 닿음)또는 탭핑(tapping) 모드 (팁이 표면을 건드리면서 진행)의 두 가지 작동 모드가 사 용된다. 캔틸레버 빔은 팁이 표면에 튕겨 지거나 끌어 당 겨지면서 편향되고 편향의 크기는 캔틸레버의 끝에서 비 스듬한 각도로 반사되는 레이저에 의해 포착된다. 반사 된 레이저 빔은 접촉 또는 탭핑 모드를 통해 획득된 표면 정보를 상관시키는 분할 포토다이오드(photodiode)에 의해 수집된다. $\mathrm{AFM}$ 은 대기, 기타 가스, 액체, 및 고 진 공 분위기 등의 조건에서 측정이 가능하다. $\mathrm{AFM}$ 의 초기 목적은 샘플의 표면 지형을 측정하는 것이었지만 $\mathrm{AFM}$ 분석 기술이 발달함에 따라 표면의 마찰 특성, 전기적 특 성 및 영 률(Young's modulus)과 같은 다양한 특성도 측 정이 가능해졌다. ${ }^{9)}$

\subsection{Electro Chemical-AFM(EC-AFM)}

$\mathrm{In}-\mathrm{situ} \mathrm{AFM}$ 과 전기화학특성 측정기로 구성된 $\mathrm{EC}-$ 


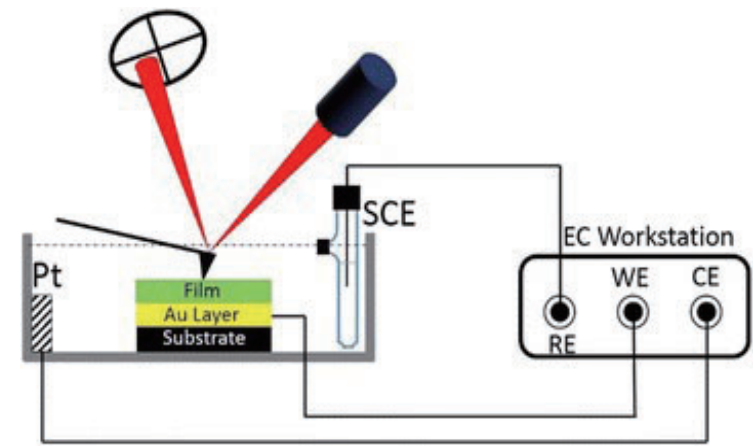

그림 2. $\mathrm{EC}-\mathrm{AFM}$ 의 개략도(RE: 기준전극; WE: 작동전극; $\mathrm{CE}$ : 상대 전극). ${ }^{10)}$

$\mathrm{AFM}$ 은 $\mathrm{AFM}$ 탐지 및 전기 화학 분석에 동시에 사용될 수 있다. (그림 2) $)^{10)}$ 전기화학특성 측정기는 작동 전극, 상대 전극 및 기준 전극을 포함하는 전형적인 3전극 시스 템을 이용하여 전기화학 특성을 측정한다.

$\mathrm{C}-\mathrm{AFM}$ 은 충/방전 사이클 동안 SEI(solid-electrolyte interphase)의 형성과 같은 전극 물질 표면의 변화를 시 각화할 수 있다. ${ }^{12-14)} \mathrm{SEI}$ 는 전해질 용액의 환원 및 산화 에 의해 전극 표면에 형성되는 피막이며 안정적인 SEI 층 은 양극의 리튬 이온 손실을 방지하여 전지가 충/방전을 거듭하면서 발생하는 용량 손실을 낮출 수 있다. 이러한 $\mathrm{SEI}$ 의 화학적 및 물리적 특성은 전해질의 조성, 전극 재 료의 유형, 형성 온도 및 충/방전 속도를 포함하여 다수 의 요인에 영향을 받으며, LIB의 전기 화학적 성능, 사이 클 특성 및 안전성을 결정하는 데 중요한 역할을 한다. ${ }^{15}$

따라서 $\mathrm{EC}-\mathrm{AFM}$ 을 이용해 음극 소재인 흑연11-13), $\mathrm{Li} 4 \mathrm{Ti} 5 \mathrm{O} 4(\mathrm{LTO})^{14)}$, 실리콘 소재 등의 $\mathrm{SEI}$ 층 형성을 관찰 하거나, 그 특성을 파악하는 연구가 다수 진행되어왔다. 예를 들어 2014년 미 육군 연구소(ARL)에서는 highly ordered pyrolytic graphite(HOPG) 물질의 SEI 층 형성 을 직접 관찰하였다. 그림 3(a)는 인가 전압에 따라 $\mathrm{HOPG}$ 전극 표면을 이미지화 한 것 인데, $2.5 \mathrm{~V}$ 에서 $2.1 \mathrm{~V}$ 범위 의 개방 회로 전압에서는 SEI 층이 형성되지 않았지만, $1.5 \mathrm{~V}$ 미만에서는 눈에 띄게 형성된 것을 확인할 수 있다. $1.0 \mathrm{~V}$ 부터는 $\mathrm{HOPG}$ 가 SEI 층으로 완전히 덮여 있는 형 상이 관찰된다. $\left.{ }^{15}\right)$ 그림 $3(\mathrm{~b}),(\mathrm{c})$ 의 Cyclic Voltammetry

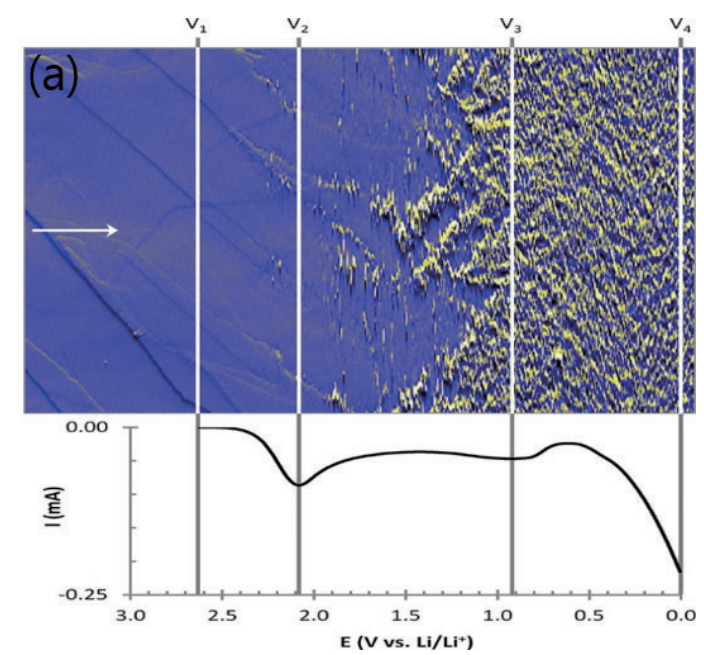

(c)
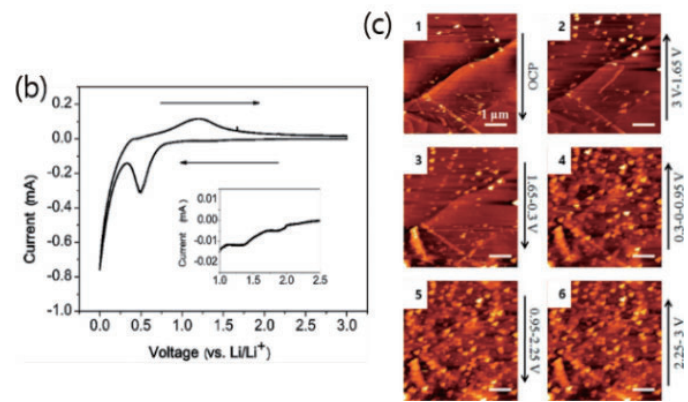

그림 3. (a)전압 변화에 따른 HOPG전극 표면 변화 이미지. (b) HOPG CV그래프 (C)CV중 HOPG전극 표면 변화 이미지. ${ }^{15)}$

(CV)와 $\mathrm{AFM}$ 형상의 상관 관계를 통해 전지의 충/방전 과정 중 흑연에서의 SEI 형성을 더 명확하게 이해할 수 있다. ${ }^{16)}$

한편 양극의 경우, 음극 소재 보다SEI 층 형성이 비교 적 어렵기 때문에 지금까지는 양극 표면 SEI층의 성장 거 동에 대한 연구가 주목을 받지 못했다. 하지만 최근 $\mathrm{LiNi}_{0.5} \mathrm{Mn}_{1.5} \mathrm{O}_{4}, \mathrm{LiFePO}_{4}$, 및 $\mathrm{LixCoO}_{2}$ 등의 양극 소재의 충/방전 시 SEI 층 형성에 대한 메커니즘을 연구하는데 $\mathrm{EC}-\mathrm{AFM}$ 이 이용되고 있다.

또한 최근에는 기존 $\mathrm{LIB}$ 에서 더 나아가 차세대 전지로

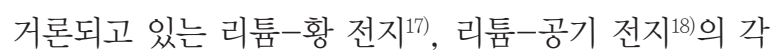
전극 표면에서의 생성물 형성과정을 연구하는데 $\mathrm{EC}-$ $\mathrm{AFM}$ 분석법이 적용되고 있다. 


\subsection{Current sensing-AFM (CS-AFM)}

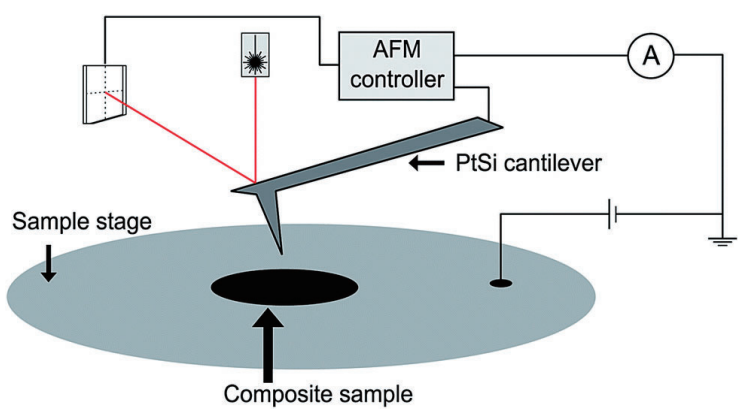

그림 4. $\mathrm{CS}-\mathrm{AFM}$ 의 개략도. ${ }^{19)}$

Conductive $\mathrm{AFM}(\mathrm{C}-\mathrm{AFM})$ 이라고도 불리는 $\mathrm{CS}-$ $\mathrm{AFM}$ 은 바이어스가 적용될 때 팁과 시료 사이에 흐르는 전류를 측정하고 기록 할 수 있다. CS-AFM은 1993년에 처음 개발되었고, $\mathrm{SiO}_{2}$ 박막 연구에 최초로 사용되었다. $\mathrm{CS}-\mathrm{AFM}$ 의 주요 구성요소는 그림 4(a)에서 볼 수 있듯 이, 전도성 프로브, 전치 증폭기 및 시료 바이어스가 있 다. $\mathrm{CS}-\mathrm{AFM}$ 는 일반 $\mathrm{AFM}$ 과는 달리 시료를 전도성 페 이스트(paste) 또는 테이프를 사용하여 고정시킨다. 시 료와 팁 사이의 바이어스(bias)는 두 구성 요소 사이에 순 수한 전류를 발생시켜 시료의 국소적 범위에서 전기적 특 성을 높은 해상도로 분석하고 기록할 수 있게 해준다.

(a)

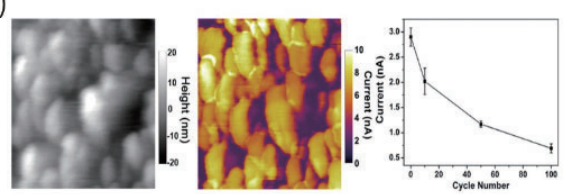

(b)
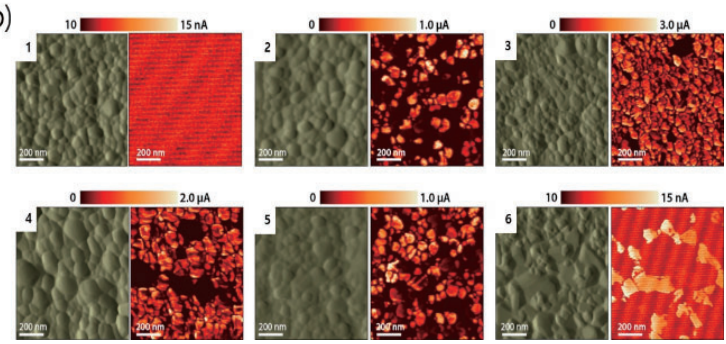

그림 5. (a) $\mathrm{LiNi}_{1 / 3} \mathrm{CO}_{1 / 3} \mathrm{Mn}_{1 / 3} \mathrm{O}_{2}$ 의 표면 지형의 EC-AFM 이미지 및 사이클에 따른 전류 변화. ${ }^{20)}(\mathrm{b}) L T O$ 표면의 사이클에 따른 EC-AFM이미지. ${ }^{19}$
$\mathrm{LIB}$ 의 전극 소재 연구에서는 $\mathrm{CS}-\mathrm{AFM}$ 을 이용하여 충/방전 동안 전극의 저항의 변화를 직접 관찰함으로써 리튬이온이 전극물질로의 삽입/탈리 시 일어나는 다양한 화학적 및 물리적 특성 변화에 대한 정보를 얻을 수 있다. 예를 들어 2013년 싱가포르 국립대학교(NUS)에서는 양 극 소재인 $\mathrm{LiNi}_{1 / 3} \mathrm{Co}_{1 / 3} \mathrm{Mn}_{1 / 3} \mathrm{O}_{2}$ 의 충/방전 사이클 수에 따 른 전기 컨덕턴스(conductance)의 변화를 $\mathrm{CS}-\mathrm{AFM}$ 을 활용하여 연구한 바 있다. ${ }^{20)}$ 그림 $5(\mathrm{a})$ 에서 보이는 바와 같이 입자 내부 영역에서 우수한 전자 전도도를 나타내고 입자 경계 혹은 입자간 간극에서는 절연 특성을 나타낸다 는 것을 알 수 있다. 그리고 사이클 수가 증가할 수록 표 면에서의 전류 값은 더 낮아지고, 이는 용량 감소 등의 전 기화학적인 열화를 초래하는 것으로 밝혀졌다. 2016년 캘리포니아 대학교 샌디에이고 캠퍼스(UCSD)에서는 음 극 소재인 LTO에 대한 연구에 CS-AFM을 활용하였다. 그림 5(b)는 $\mathrm{CS}-\mathrm{AFM}$ 을 활용하여 충/방전 시 $\mathrm{LTO}$ 의 상 변화 및 분포를 시각화함으로써 충/방전 시 $\mathrm{LTO}$ 에서의 리튬이온 삽입/탈리 과정에 대한 심도 있는 이해를 제공 한 바 있다. ${ }^{19)}$

(a)

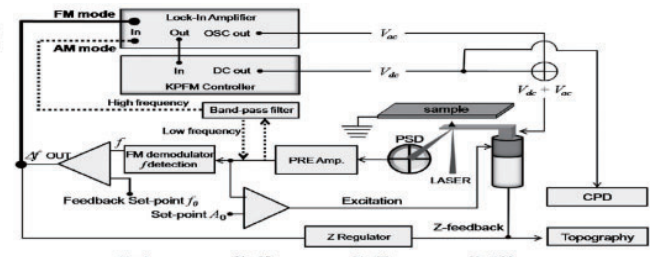

(b)
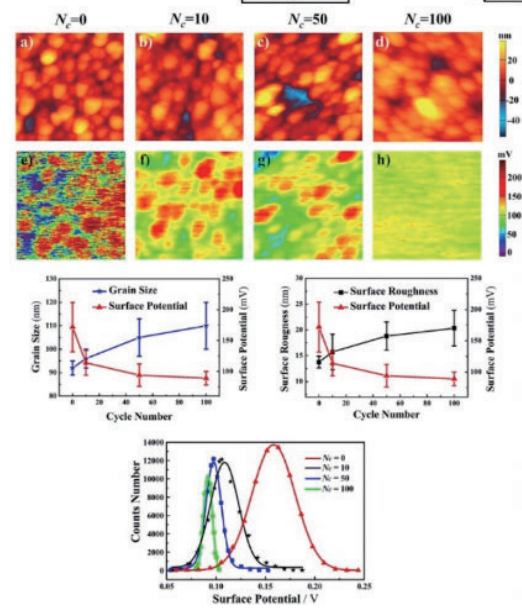

그림 6. (a)KPFM의 개략도. (b) $\mathrm{LiCoO}_{2}$ 의 사이클에 따른 표면 이미 지 및 특성 그래프. ${ }^{23)}$ 


$$
V_{C P D}=\frac{\varphi_{t}-\varphi_{S}}{e}
$$

한편, $\mathrm{CS}-\mathrm{AFM}$ 은 스캔 중 측면 마찰뿐 만 아니라 팁 과 샘플 사이의 직접적인 충돌로 인해 $\mathrm{AFM}$ 팁이 쉽게 마 모된다는 단점이 있다. 게다가, 프로브에 코팅된 전도 층 이 스캔 중 손상되면 측정 전류가 손실된 결과를 가져올 수 있다. 따라서, $\mathrm{CS}-\mathrm{AFM}$ 의 경우, 실험이 더욱 주의 깊 게 수행되어야 하고 얻어진 데이터는 표준 시료를 통해 그 신뢰도가 검증되어야만 한다.

\subsection{Kelvin probe force microscope (KPFM)}

$\mathrm{KPFM}$ 은 다양한 재료의 접촉 전위 차 $(\mathrm{CPD}$ 혹은 표면 전위)를 감지하고 측정하는 도구이다. $\mathrm{KPFM}$ 은 시료와 전도성 $\mathrm{AFM}$ 팁 사이의 표면 전위를 높은 공간분해능으로 측정가능하다. $\mathrm{KPFM}$ 은 발명된 이후로 전기장치, 반도 체 및 금속 재료의 표면 전위 및 일 함수의 특성 분석에 사용되어왔다. $\mathrm{VCPD}$ 는 다음과 같이 정의 할 수 있다.

여기서 $\Phi$ t와 $\Phi s$ 는 각각 팁과 시료의 일 함수 이고 $\mathrm{e}$ 는 기본전하이다. 팁과 시료는 서로 다른 페르미 에너지 준 위(Fermi energy level)을 나타내므로 팁이 시료 표면에 접근 할 때 전기력이 생성된다. 외부 직류 전압의 크기가 $\mathrm{VCPD}$ 와 같으면 접촉 영역의 표면 전하는 0 이므로 $\mathrm{VCPD}$ 를 얻을 수 있다. $\mathrm{KPFM}$ 에서 정 전기력은 다음의 방정식으로 계산할 수 있다.

$$
F_{\omega}=\frac{\partial C}{\partial z}\left(V_{D C} \pm V C P D\right) V_{A C} \sin (\omega t)
$$

여기서 C는 팁과 시료 사이의 커패시턴스(capacitance) 이고, $\mathrm{z}$ 는 팁과 시료 사이의 거리이며, $\mathrm{VDC}$ 와 $\mathrm{VAC}$ 는 각 각 팁에 적용된 직접 및 대체 전류의 전압이다

그림6(a)에서 볼 수 있듯이, $\mathrm{KPFM}$ 의 정 전력은 진폭 또는 주파수 변조 모드를 조절하여 $\mathrm{VCPD}$ 를 측정 할 수 있다. $\mathrm{KPFM}$ 은 표면 전위 변화를 측정하여 국소부위의 불균일성을 이미지화해서 보여준다.

$\mathrm{KFPM}$ 을 활용한 표면 전위 연구는 전극 재료의 에이징 (aging) 및 열화 메커니즘을 조사하고 해석하는데 유용 하다. 예를 들어서, $\mathrm{LiFePO}_{4}$ 양극 소재의 에이징 전, 후
의 전하 유지 능력을 조사하는데 $\mathrm{KPFM}$ 이 이용되었는 데, 연구결과 에이징된 전극이 더 낮은 전하 유지 능력을 나타내는 것을 확인하였다. ${ }^{21)}$ 또한, LIB 의 흑연 음극에 서 표면 전위 분포를 연구하는데 사용되었는데. 에이징 전과 후의 형상 분포가 다르다는 것을 확인하였다. ${ }^{22}$ $\mathrm{KPFM}$ 은 사이클링 전/후의 표면 전위와 형태 변화를 나 타내기 위해 사용되기도 했다. 그림 $6(\mathrm{~b})$ 에서 $\mathrm{LiCoO}_{2}$ 양 극 물질의 입자 크기 및 표면 거칠기는 사이클 수가 증가 할 수록 증가하고 표면 전위는 감소했다는 것을 $\mathrm{KPFM}$ 결과를 통해서 알 수 있다. ${ }^{23)}$ 이 외에도 일반적인 전극 소 재와 복합 전극 소재 간의 표면 전위 차이와 일 함수 차이 를 측정하여, 복합 전극 소재의 향상된 전기화학적 특성 에 대한 원인을 규명하는 데에 $\mathrm{KPFM}$ 이 활용되었다. ${ }^{24)}$

\subsection{AFM force spectroscopy and nano- mechanical measurements}

$\mathrm{AFM}$ 팁과 시료 사이의 상호 작용 의해 측정되는 분자 간 힘은 분자의 구조, 국소 탄성, 역학 및 기능에 의해 결 정된다. $\mathrm{AFM}$ 기반 힘 분광법은 단일 분자 수준에서 발생 하는 힘을 측정 할 수 있다. 따라서 이 기술은 분자 폴딩 (molecular folding), 수용체 및 수용체 시스템의 역학, 화학 물질 인식 등을 연구하는 데 널리 사용되어 왔다.
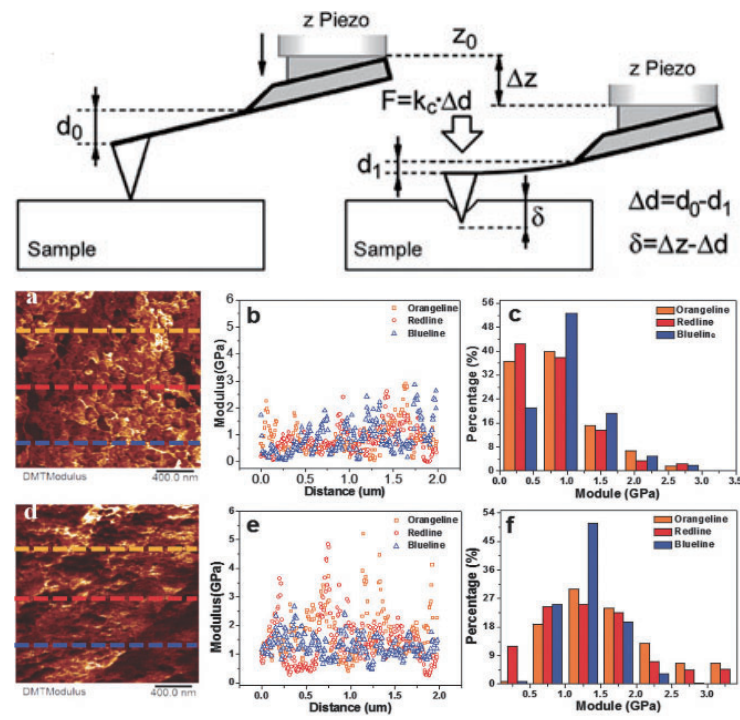

그림 8. $\mathrm{EC} / \mathrm{DMC}$ 및 FEC / DMC 전해질에서 형성된 SEㅣㅇㅢ 영 률 이미지 및 이에 대한 영 률 분포. ${ }^{28}$ 
최근에는 $\mathrm{LIB}$ 소재 연구 분야에서도 $\mathrm{SEI}$ 층을 조사하 는 데에 힘 분광법이 적용되었다. ${ }^{25)}$ 한 예로 2017년 오크 리지 연구소(ORNL)에서는 힘 분광법을 이용하여 흑연에 서 발생하는 SEI 층의 두께와 분포가 불균일한 것을 확인 한 바 있다. ${ }^{15}$

힘 분광법은 SEI 층 구조의 두께 혹은 분포 외에 다른 정보도 얻을 수 있다. 예를 들어 그림 7에서 보이는 바와 같이 SEI 층의 강도에 따라 힘-변위 곡선의 변화가 생긴 다. 이것을 통해 SEI 층의 구조적, 기계적 특성에 대한 더 깊은 이해가 가능하다. ${ }^{26,27)}$ 한편, 정량적 나노 스케일 기 계적 특성이 측정 가능해진 개선된 힘 분광법을 사용하면 영 률 또한 측정이 가능하다. 이 모드에서 AFM 팁은 모 든 스캐닝(scanning) 지점에서 힘 분광법을 수행하고 정 보를 얻으므로, 스캐닝 영역의 맵핑(mapping) 이미지를 얻을 수 있고 사이클링 전 후 전극의 영 률 변화를 알 수 있다. 중국과학원(CAS) 닝보 재료 기술연구소에서는 2017년 이 기술을 이용해 흑연에서 SEI 층은 FEC/DMC 전해질을 사용할 때 $\mathrm{EC} / \mathrm{DMC}$ 보다 더 많이 형성된다는 것 을 확인한 바 있다 (그림 8). ${ }^{28)}$ 위 방법을 이용한 다른 연 구로는 이온성 액체(ionic liquids)이나 유기 용매 전해질 을 사용한 폴리프로필렌(polypropylene) 분리막의 영 률 및 관련 기계적 특성을 측정한 연구들이 있다. ${ }^{29)}$

한편, 힘 분광법은 SEI 층이 전극에 미치는 영향을 연 구하는 데에도 적용이 가능하다. 2017년 닝보 재료 기술 연구소에서는 마이크로 및 나노 크기 실리콘 전극에 형성 된 SEI 층의 영률(Young' modulus)을 연구하였다. $1 \mathrm{M}$ $\mathrm{LiPF} 6 / \mathrm{EC} / \mathrm{DMC}$ 의 전해질에서 충/방전 후, 마이크로,

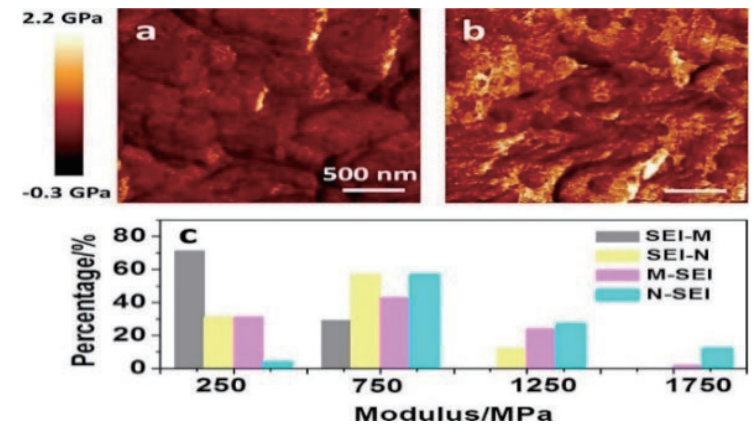

그림 9. SEI-M, SEI-N의 계수 이미지 및 영 률 분포. ${ }^{30)}$
나노 사이즈의 실리콘에 형성된 SEI 층의 영률은 각각 457 및 $749 \mathrm{MPa}$ 였다. $1 \mathrm{M} \mathrm{LiPF} 6 / \mathrm{FEC} / \mathrm{DMC}$ 전해질에 서 사이클링 한 후 이 값은 각각 686 및 $980 \mathrm{MPa}$ 로 높아 졌다. 따라서, 마이크로 실리콘 입자에 형성된 SEI 층은 나노 실리콘 입자에 형성된 것보다 낮은 강성을 갖는 것 을 알 수 있다 (그림 10). $\left.{ }^{30}\right)$

2014년 중국 과학 기술 대학교(USTC) 연구팀은 첨가 제의 유무에 따라 $\mathrm{MnO}$ 박막 전극에 형성된 SEI 층의 두 께와 영률이 어떠한 상관 관계를 갖는지 힘 분광법을 통 해 연구한 바 있다. ${ }^{31)} \mathrm{VC}$ (vinylene carbonate) 첨가제를 전해질에 첨가한 경우, 충전 시에 안정성이 개선되는 대 신 SEI층이 부분적으로 분해된다는 단점이 있다. 형성된 $\mathrm{SEI}$ 층의 기계적 특성은 열악하지만 전기화학적 안정성 을 향상시켜 사이클링 중 전해질 손실을 방지 할 수 있는 Lithium bis (oxalate) borate LiBOB를 VC와 혼합하여 첨가할 경우 흥미롭게도, 사이클링시에 안정하고 전해질 이 분해되지 않는 SEI 층이 형성되었다. 이처럼 실제 힘 분광법을 사용한 SEI의 분석을 통해 첨가제의 효과를 확 인할 수 있다.

\subsection{Scanning electrochemical microscopy (SECM)}

$\mathrm{SECM}$ 은 계면의 전기 화학 과정을 조사할 수 있는 기 술이다. SECM의 기본 원리는 그림 10 에 도시되어 있다. 모바일 초 미세 전극 (UME) 프로브의 정확한 3 차원 위 치로 인해 국소적인 산화, 환원 반응에 의해 생성 된 전류 를 측정할 수 있다. 따라서, 시료의 화학적 활성을 포착 하고 맵핑할 수 있다. ${ }^{32)} \mathrm{SECM}$ 작동 모드에는 피드백, 생 성 수집, 침투, 이온 전달, 평형 섭동, 전위차 감지 등과 같은 다양한 모드가 있다. ${ }^{33)}$ 이 중 피드백 모드가 가장 널리 사용되며 이는 네거티브(negative) 및 포지티브(positive) 피드백 모드를 포함한다.

피드백 모드의 기본 원리는 다음과 같다. ${ }^{34)}$ 전극이 전 기 활성 물질 용액에 삽입되고 전극에 음의 전위가 적용 되면 다음과 같은 산화 반응이 발생한다.

$$
\mathrm{R}--\mathrm{ne}-\rightarrow 0
$$

프로브가 기판에서 멀리 떨어져 있을 때 프로브의 안정 
된 확산 전류는 다음 방정식으로 주어진다.

$$
\mathrm{i}_{\mathrm{T}, \infty}=4 \mathrm{nFD}_{\mathrm{R}} \mathrm{C}_{\mathrm{R}}
$$

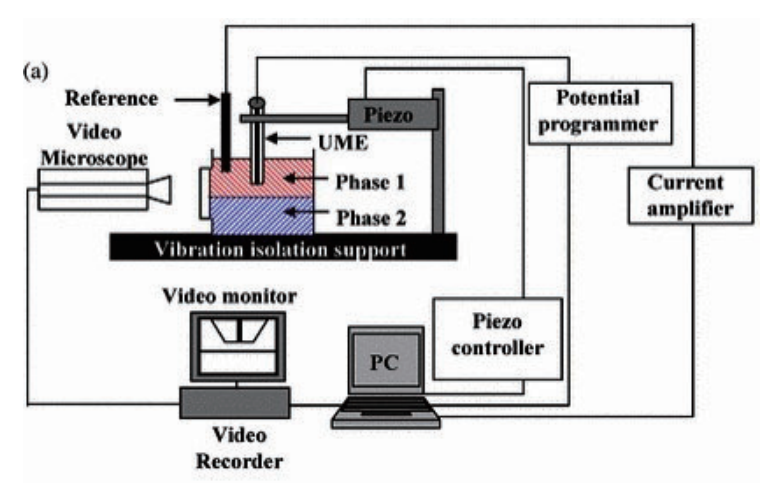

(b)

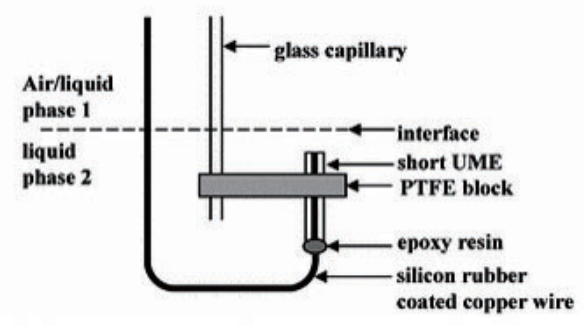

그림 10. SECM 및 submarine 전극의 개략도32)

여기서 iT, $\infty$ 는 프로브의 안정된 확산 전류이며, n은 전자 이동 수, $\mathrm{F}$ 는 패러데이 상수다. $\mathrm{DR}$ 은 확산 계수이 고, $\mathrm{CR}$ 은 $\mathrm{R}$ 의 농도이며, $\mathrm{a}$ 는 프로브의 반경이다.

프로브가 기판에 충분히 가까이 있을 때나 기판이 도체 인 경우, 발생 된 $\mathrm{O}$ 는 기판으로 확산 된 후 $\mathrm{R}$ 로 환원 될 수 있다. 따라서 환원 및 산화 반응의 사이클이 일어날 수 있으며, 프로브 iT의 전류는 iT, $\infty$ 보다 클 것이다. 이를 포지티브 피드백 모드라고 한다. 반대로 기판이 절연체인 경우 프로브 iT의 전류는 iT, $\infty$ 보다 작으므로 네거티브 피드백 모드라고 한다. ${ }^{33)}$

Bard가 발명 한 SECM은 표면 형태 뿐만 아니라 전기 화학적 역학, 전기 화학적 활성, 전기 촉매, 전하 이동 매 커니즘 및 도체와 절연체의 표면 반응성과 관련된 기타 특성을 관찰하는 중요한 도구가 되었다. ${ }^{35)}$ 또한 $\mathrm{SECM}$ 은 in-situ 및 operando모드로 LIB 소재를 조사하는 데 널
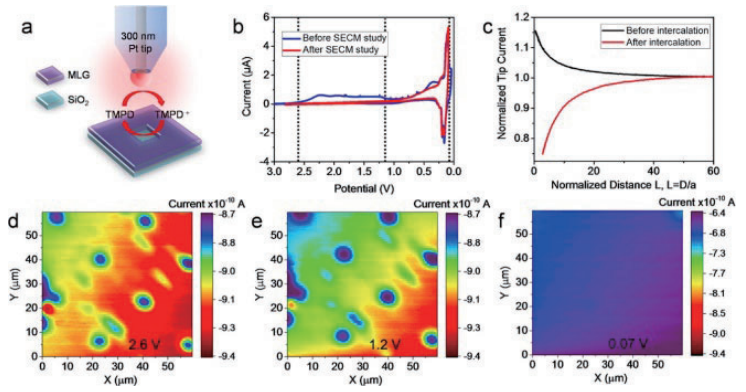

그림 11. 패턴화된 다층 그래핀 상에 SE 형성의 피드백 SECM 이미지. ${ }^{38}$

리 사용되었다.

2017년 옥스포드 대학교에서는 양극 물질에 3개의 상 이한 높은 작동전압에서 형성된 $\mathrm{SEI}$ 층의 형성 공정 및 전자 특성을 SECM in-situ모드를 통해 측정하였다. 이 연구는 고 에너지 밀도 $\mathrm{LIB}$ 를 개발하는 길을 열었다. ${ }^{36)}$ 또한, 2016년 칼덴오시츠키 대학에서는 $\mathrm{HOPG}$ 및 흑연 복합체 표면에 형성된 다양한 SEI 층의 특성을 측정하는 데 $\mathrm{SECM}$ 을 사용하여 $\mathrm{HOPG}$ 에서 형성된 $\mathrm{SEI}$ 층이 흑연 에서 형성된 SEI 층 보다 더 안정적임을 밝혀냈다. ${ }^{37)}$

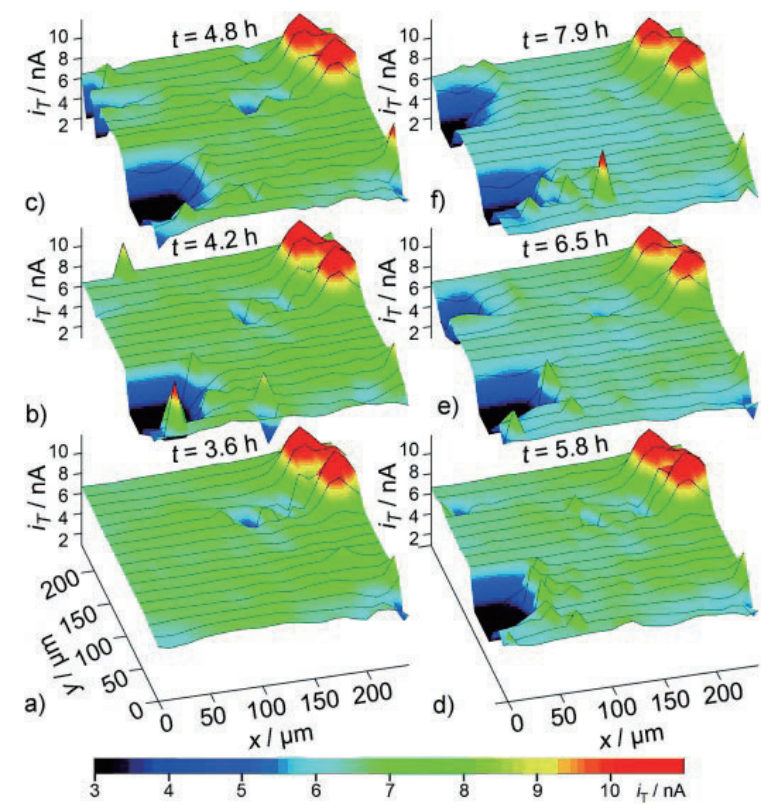

그림 12. SECM 셀에서 전해질 용액을 충전 한 후 기록 된 SEI- 피복 흑 연 전극의 동일한 영역에 대한 SECM 피드백 이미지 내 가스버블 형성의 검출. 39 ) 
2016년 일리노이대학교 어바나-샴페인캠퍼스에서는 $\mathrm{SEI}$ 층의 형성 및 특성에 대한 $\mathrm{VC}$ 첨가의 효과를 $\mathrm{SECM}$ 을 이용해 연구한 바 있다. $\mathrm{VC}$ 가 없는 전해질에서 $\mathrm{SEI}$ 는 $0.8 \mathrm{~V}$ 에서 형성되기 시작하였고, $\mathrm{VC}$ 함유 전해질에서 $1.3 \mathrm{~V}$ 로 증가 하였다. $\mathrm{VC}$ 분해의 초기 단계에서, 이종 전 자 절연 층이 형성되는 것을 확인하였고 균일한 $\mathrm{SEI}$ 층을 형성하기 위해, 전위는 $0.8 \mathrm{~V}$ 보다 더 높아야 한다는 사실 을 밝혀냈다. 또한 연구팀은 SEI 층의 형성 이외에도 SEI 층의 성장 과정에서 다층 그래핀(graphene)의 표면 전도 성의 변화를 $\mathrm{SECM}$ 를 이용하여 관찰하였다. 연구팀은 그 래핀에서 리튬 이온 삽입을 가능하게 하는 이온 채널의 역할을 최근에 개발 된 리튬 이온 이미징(imaging) 기술 을 사용하여 입증하였다. 이 결과는 $\mathrm{SECM}$ 이 그래핀 소 재에서의 이온 및 전자 거동을 분석하기 위한 강력한 기 술임을 입증한다 (그림 11). ${ }^{38)}$

a
Topography

b Topography

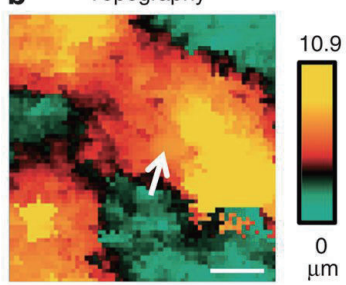

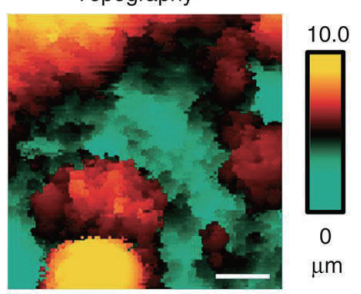

Potential

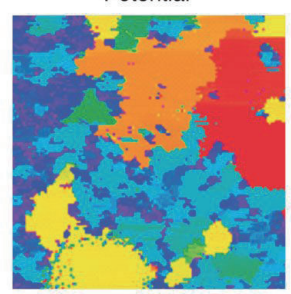

Potential

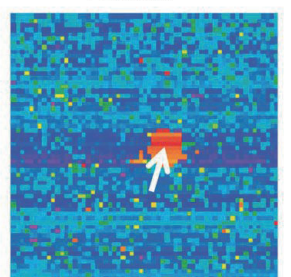

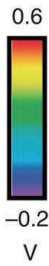

0.95

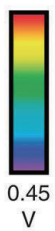

그림 13. LFFePO4 전극의 topography 및 포텐셜 이미지. ${ }^{43}$

$\mathrm{LIB}$ 에서 사이클링 중 가스 생성은 배터리의 안전성 및 신뢰성에 중요한 영향을 미친다. $\mathrm{SECM}$ 은 가스 형성 및 분리 과정을 실시간으로 감지할 수 있다. 그림 12 에서 확 인할 수 있듯이, SECM을 이용해 LIB 사이클링 시 가스 형성 및 분리에 의해 흑연 소재에 형성된 $\mathrm{SEI}$ 층의 기계 적 파괴 및 변형 현상을 확인 할 수 있었다. ${ }^{39)} \mathrm{SECM}$ 을 통
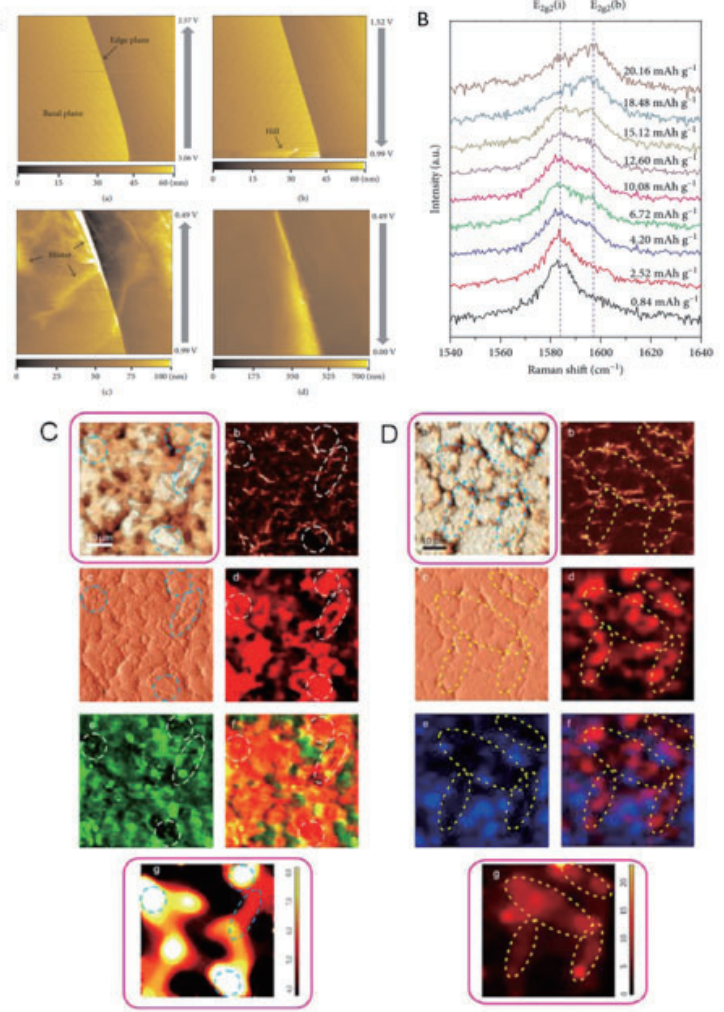

한 가스 생성 및 수집 실험은 리튬-공기 전지에서의 공 기 전극을 지나는 전해질로 유입되는 $\mathrm{O}_{2}$ 를 탐지하는데 도 사용될 수 있다. 이 방법은 리튬-공기 전지의 방전 과 정에서 공기 전극을 통한 산소 투과에 대한 다른 유사 연구 에 적용된 바 있다. ${ }^{40)}$ 리튬 이온 및 다른 알칼리 이온전도 도는 $\mathrm{Hg} / \mathrm{Pt} \mathrm{UME}$ 가 제공된 SECM으로 분석할 수 있다.

기본 $\mathrm{SECM}$ 의 리튬 이온 농도 감지 한계는 $20 \mu \mathrm{M}$ 로 낮 다. 따라서, $\mathrm{Hg} / \mathrm{Pt} \mathrm{UME}$ 를 활용하는 모드가 도입되었다. 이 모드는 리튬 및 다른 알칼리 이온에 대한 신뢰성 있는 데이터를 신속하게 얻을 수 있고 재료 결함이 반응 균일 성에 미치는 영향을 높은 공간적 및 시간적 분해능으로 규명할 수 있는 새로운 방법이다. ${ }^{41)}$

2018년 싱가포르 국립 대학교(NUS)에서는 처음으로

그림 14. (a) $1 \mathrm{M} \mathrm{LiClO} / \mathrm{PC}$ 에서 첫 방전 과정 동안 얻은 $\mathrm{HOPG}$ 의 in-situ $\mathrm{AFM}$ 이미지. (b) $1 \mathrm{M} \mathrm{LiClO} / \mathrm{PC}$ 정전류 모드에서 첫 번째 환원 동안 기록된 HOPG의 in-situ라만 스펙트럼. ${ }^{45)}$ (c) 새 배터리 음 극의 AFM 및 라만 이미지. (d) 오래된 배터리에서 제거 된 동일 한 음극 위치의 AFM 및 라만 이미지 ${ }^{46)}$ 
$\mathrm{SECM}$ 을 이용하여 $\mathrm{LiFePO}_{4} / \mathrm{FePO}_{4}$ 의 사이클링 시 리튬 이온의 반응 속도 상수 (rate constant)를 계산하였다. 또한 위 연구팀은 시간대전류법을 $\mathrm{SECM}$ 에 적용하여 $\mathrm{LiFePO}_{4} / \mathrm{FePO}_{4}$ 의 사이클링 시 상전이 메커니즘의 통상 적인 수축 코어 모델을 반박 하였다. ${ }^{42)}$

좀 더 고성능인 SECM모드로는 주사 전기 화학 셀 현 미경(SECCM)모드가 있다. SECCM모드는 약 $100 \mathrm{~nm}$ 의 해상도로 전극의 형태와 전기화학적 특성을 동시에 매핑 할 수 있게 개발된 모드이다. 최근에 $\mathrm{LiFePO}_{4}$ 와 같은 양 극의 전기화학적 특성을 조사하기 위해 사용되었다(그림 13). ${ }^{43)}$

\subsection{AFM in combination with spectroscopy}

앞서 서술 한 바와 같이, 다양한 모드에서 동작하는 $\mathrm{AFM}$ 은 LIB 소재의 다양한 특성을 분석하는데 사용될 수 있다. 그러나 전극의 화학적 그룹, 분자 구조 및 화학적 조성은 $\mathrm{AFM}$ 에 의해서는 직접 얻을 수 없다. 따라서 $\mathrm{AFM}$ 과 라만(Raman) 및 푸리에 변환 적외선 분광법 (FT-IR)과 같은 다른 분광법을 결합하여 사용하는 것이 이를 이해하는데 도움이 될 것이다. AFM 및 라만 분광법 을 결합하여 적용된 예로, 2018년 순천향대학교에서 그 림 14(a), (b)에 도시 된 바와 같이 $\mathrm{LiClO} 4 / \mathrm{PC}$ 전해질 내 에 있는 $\mathrm{HOPG}$ 에서 리튬 이온의 산화, 환원 반응을 조사 하기 위해 결합된 분석법을 사용하였다. ${ }^{45)}$ 분석 결과를 통해 높은 전류 밀도에서 반응은 가역적이고 높은 쿨롱 효율(Coulombic efficiency)을 달성할 수 있으며, 용량 에 영향을 미친다는 것을 명확하게 보여주었다. 이 결과 는 시료에서 용매 공동 삽입(co-intercalation) 및 분해 현상을 규명해주었다. 위 방법을 이용한 다른 연구들로는 실리콘 박막 음극의 $\mathrm{LiPON}$ 기반 인공 $\mathrm{SEI}$ 층에 대한 연 구가 있다. ${ }^{44)}$

또한 $\mathrm{AFM}$ 과 라만 분광법을 결합하여 양극의 동일한 영 역을 매핑함으로 리튬 이온 삽입 거동을 예측할 수 있다. 그림 $14(\mathrm{c}),(\mathrm{d})$ 는 $\mathrm{LiCoO}_{2}$ 양극을 위의 방법을 통하여 분 석한 결과이다. 이 결과를 통해 시료의 화학적 조성을 알 수 있다. 그리고 리튬 이온이 탈리된 영역은 녹색, 리튬 이온이 삽입된 영역은 빨간색으로 표시된 것을 바탕으로
새 배터리와 오래된 배터리의 양극을 구별할 수 있다. ${ }^{46)}$ 최근에 개발된 단일 입자 마이크로 라만 분광법은 단일 입자 마이크로 배터리 및 마이크로 전극에 대한 분광 전 기화학 연구를 할 수 있게 해주었다. 라만 분광법의 소형 화는 개별 입자의 충전 상태를 모니터링 할 수 있게 하며, $\mathrm{LIB}$ 에서 전하 흐름을 시각화하는 새로운 방법이 될 것이 다. 예를 들어, 단일 입자 $\mathrm{LiMn}_{2} \mathrm{O}_{4}$ 전극이 이 방법에 의 해 조사되었다. ${ }^{47)}$ 또한, 전기화학 $(\mathrm{EC})$ - 팁 강화 라만분광 법(TERS)을 주사 터널링 현미경(STM)과 결합하여 ECSTM-TERS 플랫폼(platform)을 형성할 수 있다. 이 플 랫폼에 사용된 팁의 in-situ chemical functionalization 은 플랫폼이 분자 수준에서 $\mathrm{LIB}$ 소재의 계면 특성을 연구 하기 위한 이상적인 방법이 된다. ${ }^{48)}$

\section{Future and outlooks}

$\mathrm{AFM}$ 의 다양한 모드 및 기능은 표면 형태를 관찰하기 위해 사용될 뿐 만 아니라 리튬 이온 삽입/탈리 과정을 조 사하기 위해서도 사용되어왔다. AFM은 LIB 전극 소재 의 SEI 층의 물성에 대한 다양한 정보를 측정 가능하며, $\mathrm{SEI}$ 층을 in-situ방식으로 연구하기 위한 유용한 방법으 로 많은 LIB 관련 연구에서 활용되었다.

$\mathrm{AFM}$ 기술의 큰 발전에도 불구하고 $\mathrm{LIB}$ 전극의 $\mathrm{SEI}$ 층 및 계면과 관련된 수많은 특성과 메커니즘은 여전히 밝혀 져 있지 않다. 예를 들어, 리튬 금속의 활성 표면은 유기 전해질에서 안정한 $\mathrm{SEI}$ 층을 형성하는 것을 어렵게 하고, 동시에 리튬 금속 음극의 수지 상(dendrite) 성장과 관련 된 안전성 문제를 촉진시킨다는 문제가 있다. In-situ $\mathrm{EC}-\mathrm{AFM}$ 및 $\mathrm{KPFM}$ 과 같은 고급 $\mathrm{AFM}$ 기술은 다양한 조 건 하에서 전극 및 계면의 구조적 및 기계적 물성 변화를 관찰할 수 있기 때문에 위의 관련 연구에 유용하게 사용 될 수 있다. 하지만 $\mathrm{AFM}$ 기술에는 이와 같은 장점들 이 외에도 한계점 또한 존재한다. 예를 들어, 시료의 표면 (100 nm 미만 깊이)만을 측정할 수 있고, 이미지를 얻는 데 오랜 시간 (수 분 수준)이 필요하다. 빠른 스캔이 가능 한 $\mathrm{AFM}$ 이 개발되었지만 상용화가 되기까지는 다소 시간 이 걸릴 것으로 예상된다. LIB 소재의 미결된 문제를 해 
결하기 위해서는 휠씬 더 복잡한 접근법이 필요하다. 따 라서, 새로운 $\mathrm{AFM}$ 모드가 지속적으로 개발됨에 따라 향 후 개선된 $\mathrm{AFM}$ 이 LIB 소재 연구에 더 많은 부분 기여할 수 있다고 생각한다.

\section{참고문헌}

1. K.I. Ozoemena, Shaowei Chen, "Nanomaterials in Advanced Batteries and Supercapacitors", Springer, (2016)

2. C. Curry, "Lithium ion battery costs and market", Bloomberg New Energy Finance,"(2017).

3. Y.J. Yang, X.Z. Liu, Z.H. Dai, F.L. Yuan, Y. Bando, D. Golberg, X. Wang, "In Situ electrochemistry of rechargeable battery materials: status report and perspectives," Adv. Mater 2922 (2017).

4. J.M. Tarascon, M. Armand, "Issues and challenges facing rechargeable lithium batteries," Nature 414 $359-367$ (2001)

5. Y.-Z. Su, Y.-C. Fu, Y.-M. Wei, J.-W. Yan, B.-W. Mao, "The electrode/ionic liquid interface: electric double layer and metal electrodeposition," ChemPhys Chem 112764 - 2778 (2010).

6. Z. Zhu, X. Chen, "Artificial interphase engineering of electrode materials to improve the overall performance of lithium-ion batteries," Nano Res. 10 4115-4138 (2017).

7. L. Danis, S.M. Gateman, C. Kuss, S.B. Schougaard, J. Mauzeroll, "Nanoscale measurements of Lithiumion-battery materials using scanning probe techniques," ChemElectroChem 4 6-19 (2017).

8. S. Yang, J.X. Wu, B.G. Yan, L. Li, Y. Sun, L. Lu, K. Zeng, "Nanoscale characterization of charged/ discharged lithium-rich thin film cathode by scanning probe microscopy techniques," J. Power Sources 352 9 - 17(2017).

9. H.J. Butt, B. Cappella, M. Kappl, "Force measurements with the atomic force microscope: technique, interpretation, and applications," Surf. Sci. Rep 59 $1-152$ (2003).

10. J.V. Macpherson, P.R. Unwin, "Combined scanning electrochemical-atomic force microscopy," Anal. Chem. 72 276-285(2000).

11. A.M. Tripathi, W.N. Su, B.J. Hwang, "In situ analytical techniques for battery interface analysis," Chem. Soc. Rev 47736 - 851 (2018).
12. F. Dinkelacker, P. Marzak, J. Yun, Y. Liang, A.S. Bandarenka, "A Multistage Mechanism of Lithium Intercalation into Graphite Anodes in Presence of the Solid Electrolyte Interface," ACS Appl. Mater. Interfaces (2018).

13. T. Minato, T. Abe, "Surface and interface sciences of Li-ion batteries-Research progress in electrode electrolyte interface," Prog. Surf. Sci 92 240-280 (2017).

14. R. Guo, W. Yue, Y. Ren, W. Zhou, "Hierarchical structured graphene/metal oxide porous carbon composites as anode materials for lithium-ion batteries," Mater. Res. Bull 73 102-110(2016).

15. S.J. An, J.L. Li, C. Daniel, D. Mohanty, S. Nagpure, D.L. Wood, "The state of understanding of the lithium-ion-battery graphite solid electrolyte interphase (SEI) and its relationship to formation cycling," Carbon 105 52-76(2017).

16. K.A. Hirasawa, K. Nishioka, T. Sato, S. Yamaguchi, S. Mori, "Investigation of graphite composite anode surfaces by atomic force microscopy and related techniques," J. Power Sources 69 97-102(1997).

17. S. Huang, L. $-Z$. Cheong, S. Wang, D. Wang, C. Shen, "In-situ study of surface structure evolution of silicon anodes by electrochemical atomic force microscopy," Appl. Surface Sci. 45267 - 74(2018).

18. S.Y. Lang, Y. Shi, Y.G. Guo, D. Wang, R. Wen, L.J. Wan, "Insight into the interfacial process and mechanism in lithium-sulfur batteries: an In Situ AFM study," Angew. Chem.-Int. Edit 55 1583515839(2016).

19. R. Wen, M. Hong, H.R. Byon, "In Situ AFM imaging of $\mathrm{Li}-\mathrm{O}_{2}$ electrochemical reaction on highly oriented pyrolytic graphite with ether-based electrolyte," $J$. Am. Chem. Soc. 135 10870-10876(2013).

20. R. Wen, H.R. Byon, "In situ monitoring of the $\mathrm{Li}-\mathrm{O}_{2}$ electrochemical reaction on nanoporous gold using electrochemical AFM," Chem. Commun 50 (2014) $2628-2631$

21. S.C. Nagpure, B. Bhushan, S.S. Babu, "Surface potential measurement of aged $\mathrm{Li}$-ion batteries using Kelvin probe microscopy," J. Power Sources 196 $1508-1512(2011)$.

22. S.Y. Luchkin, H.Y. Amanieu, D. Rosato, A.L. Kholkin, "Li distribution in graphite anodes: a Kelvin Probe Force Microscopy approach,” J. Power Sources 268887 - 894(2014). 
23. J.X. Wu, S. Yang, W. Cai, Z.F. Bi, G.Y. Shang, J.N. Yao, "Multi-characterization of $\mathrm{LiCoO}_{2}$ cathode films using advanced AFM-based techniques with high resolution," Sci Rep 7 9(2017).

24. K.Q. Zhou, M.L. Kang, X.Q. He, Z.S. Hong, Z.G. Huang, M.D. Wei, "A multi-functional gum arabic binder for $\mathrm{NiFe}_{2} \mathrm{O}_{4}$ nanotube anodes enabling excellent Li/Na ion storage performance," J. Mater. Chem. A5 18138-18147(2017).

25. S.D. Lacey, J. Wan, A.v.W. Cresce, S.M. Russell, J. Dai, W. Bao, K. Xu, L. Hu, "Atomic force microscopy studies on molybdenum disulfide flakes as sodiumion Anodes", Nano Lett. 15 1018-1024 (2015).

26. J. Zhang, R. Wang, X.C. Yang, W. Lu, X.D. Wu, X.P. Wang, H. Li, L.W. Chen, "Direct Observation of Inhomogeneous Solid Electrolyte Interphase on $\mathrm{MnO}$ Anode with Atomic Force Microscopy and Spectroscopy", Nano Lett 12 2153-2157 (2012).

27. Y. Gu, W.W. Wang, Y.J. Li, Q.H. Wu, S. Tang, J.W. Yan, M.S. Zheng, D.Y. Wu, C.H. Fan, W.Q. Hu, Z.B. Chen, Y. Fang, Q.H. Zhang, Q.F. Dong, B.W. Mao, "Designable ultra-smooth ultra-thin solidelectrolyte interphases of three alkali metal anodes", Nat. Commun 9 (2018).

28. C. Shen, G. Hu, L. -Z. Cheong, S. Huang, J.-G. Zhang, D. Wang, "Direct observation of the growth of lithium dendrites on graphite anodes by operando EC-AFM", Small Methods 21700298 (2017).

29. J.H. Chen, H.J. Hu, S. Li, Y.L. He, "Evolution of mechanical properties of polypropylene separator in liquid electrolytes for lithium-ion batteries", J. Appl. Polym. Sci. 13511 (2018).

30. S.Q. Huang, L.Z. Cheong, S.W. Wang, D.Y. Wang, C. Shen, "In-situ study of surface structure evolution of silicon anodes by electrochemical atomic force microscopy", Appl. Surf. Sci 45267 - 74 (2018).

31. J. Zhang, X.C. Yang, R. Wang, W.L. Dong, W. Lu, X.D. Wu, X.P. Wang, H. Li, L.W. Chen, "Influences of additives on the formation of a solid electrolyte interphase on mno electrode studied by atomic force microscopy and force spectroscopy", J. Phys. Chem. C 11820756 - 20762 (2014).

32. A.J. Bard, G. Denuault, C. Lee, D. Mandler, D.O. Wipf, "Scanning electrochemical microscopy - a new technique for the characterization and modification of surfaces", Accounts Chem. Res 23 357-363 (1990).

33. J. Kwak, A.J. Bard, "Scanning electrochemical microscopy - theory of the feedback mode", Anal. Chem $611221-1227$ (1989).

34. F.O. Laforge, J. Velmurugan, Y.X. Wang, M.V. Mirkin, "Nanoscale imaging of surface topography and reactivity with the scanning electrochemical microscope", Anal. Chem 813143 - 3150 (2009).

35. G. Zampardi, R. Trocoli, W. Schuhmann, F. La Mantia, "Revealing the electronic character of the positive electrode/electrolyte interface in lithium-ion batteries", Phys. Chem. Chem. Phys 19 28381-28387 (2017).

36. H. Bulter, F. Peters, G. Wittstock, "Scanning Electrochemical microscopy for the insitu characterization of solid-electrolyte interphases: highly oriented pyrolyticMgraphite versus graphite composite", Energy Technol 4 1486-1494 (2016).

37. J. Hui, M. Burgess, J. Zhang, J. Rodríguez-López, "Layer number dependence of $\mathrm{Li}+$ intercalation on few-layer graphene and electrochemical imaging of its solid--electrolyte interphase evolution”, ACS Nano 104248 - 4257 (2016).

38. H. Bulter, F. Peters, J. Schwenzel, G. Wittstock, "Spatiotemporal changes of thesolid electrolyte interphase in lithium-ion batteries detected by scanning electrochemical microscopy", Angew. Chem. -Int. Edit 53 10531-10535 (2014).

39. P. Schwager, D. Fenske, G. Wittstock, "Scanning electrochemical microscopy of oxygen permeation through air-electrodes in lithium-air batteries", $J$. Electroanal. Chem. 740 82-87 (2015).

40. Z.J. Barton, J. Rodriguez-Lopez, "Lithium ion quantification using mercury amalgams as in situ electrochemical probes in nonaqueous media”, Anal. Chem 86 10660 - 10667(2014).

41. E. Ventosa, E. Madej, G. Zampardi, B. Mei, P. Weide, H. Antoni, F. La Mantia, M. Muhler, W. Schuhmann, "Solid Electrolyte Interphase (SEI) at $\mathrm{TiO}_{2}$ Electrodes in Li-Ion Batteries: defining Apparent and Effective SEI Based on Evidence from X-ray Photoemission Spectroscopy and Scanning Electrochemical Microscopy", Acs Appl. Mater. Interfaces 9 31233130 (2017).

42. R.T. Yan, J. Ghilane, K.C. Phuah, T.N.P. Truong, S. Adams, H. Randriamahazaka, Q. Wang, "Determining $\mathrm{Li}^{+}$-coupled redox targeting reaction kinetics of battery materials with scanning electrochemical microscopy”, J. Phys. Chem. Lett. 9 491-496 (2018). 


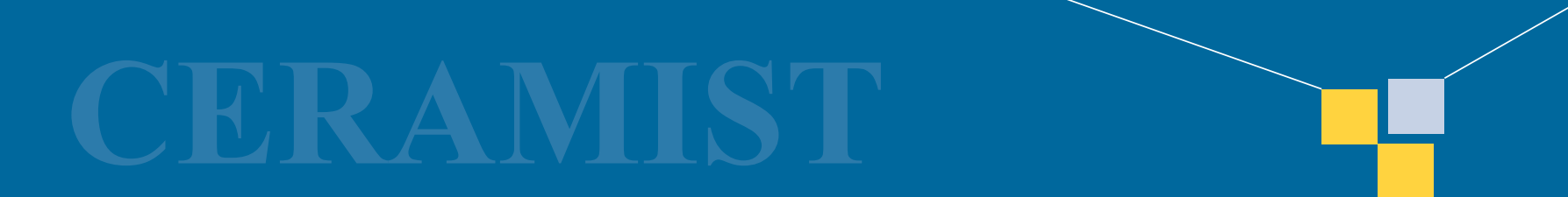

특 집 ㅁ 이지현, 공상혁, 김형우, 김형석

43. Y. Takahashi, A. Kumatani, H. Munakata, H. Inomata, K. Ito, K. Ino, H. Shiku, P.R. Unwin, Y.E. Korchev, K. Kanamura, T. Matsue, "Nanoscale visualization of redox activity at lithium-ion battery cathodes", Nat. Commun. 57 (2014).

44. T.M. McEvoy, K.J. Stevenson, "Spatially Resolved Imaging of Inhomogeneous Charge Transfer Behavior in Polymorphous Molybdenum Oxide. I. Correlation of Localized Structural, Electronic, and Chemical Properties Using Conductive Probe Atomic Force Microscopy and Raman Microprobe Spectroscopy", Langmuir 213521 - 3528 (2005).

45. H.Y. Song, S.K. Jeong, "Electrochemical solvent cointercalation into graphite in propylene carbonate-
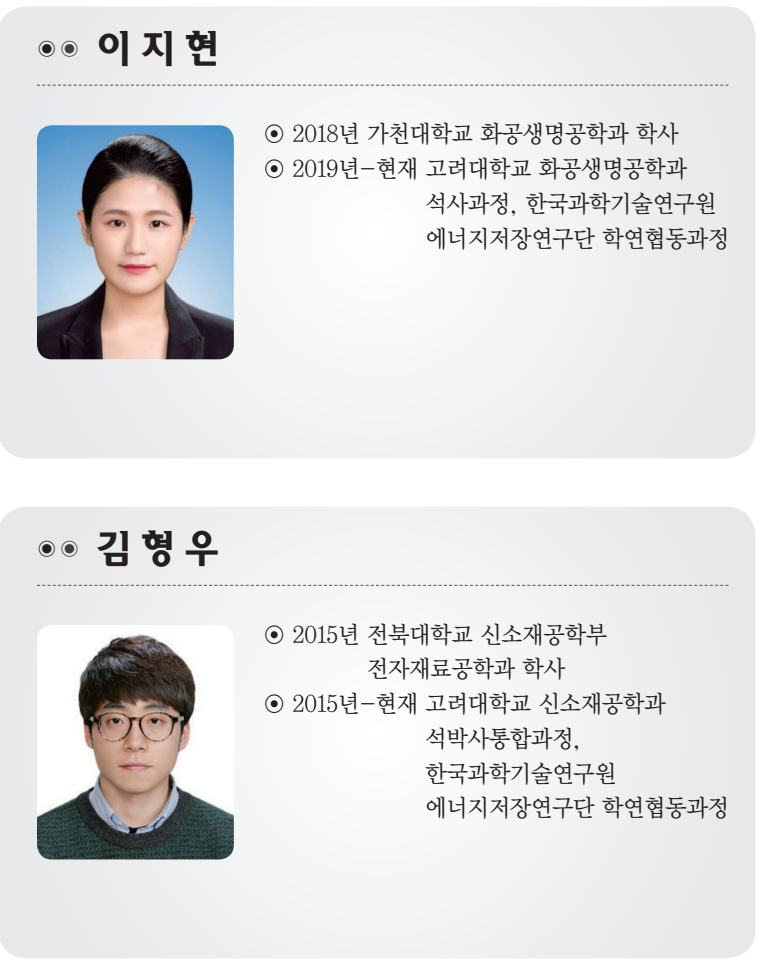

based electrolytes: a chronopotentiometric characterization", J. Anal. Methods Chem 5 (2018).

46. K. Ozawa, "Lithium Ion Rechargeable Batteries: Materials, Technology, and New Applications", Wiley-VCH Verlag GmbH \& Co, KGaA, (2010).

47. A.J.J. Jebaraj, D.A. Scherson, "Microparticle Electrodes and Single Particle Microbatteries: electrochemical and in Situ MicroRaman Spectroscopic Studies", Accounts Chem. Res 461192 -1205 (2013).

48. G. Goubert, X. Chen, S. Jiang, R.P. Van Duyne, "In Situ Electrochemical Tip-Enhanced Raman Spectroscopy with a Chemically Modified Tip”, J. Phys. Chem. Lett. 93825 - 3828 (2018).
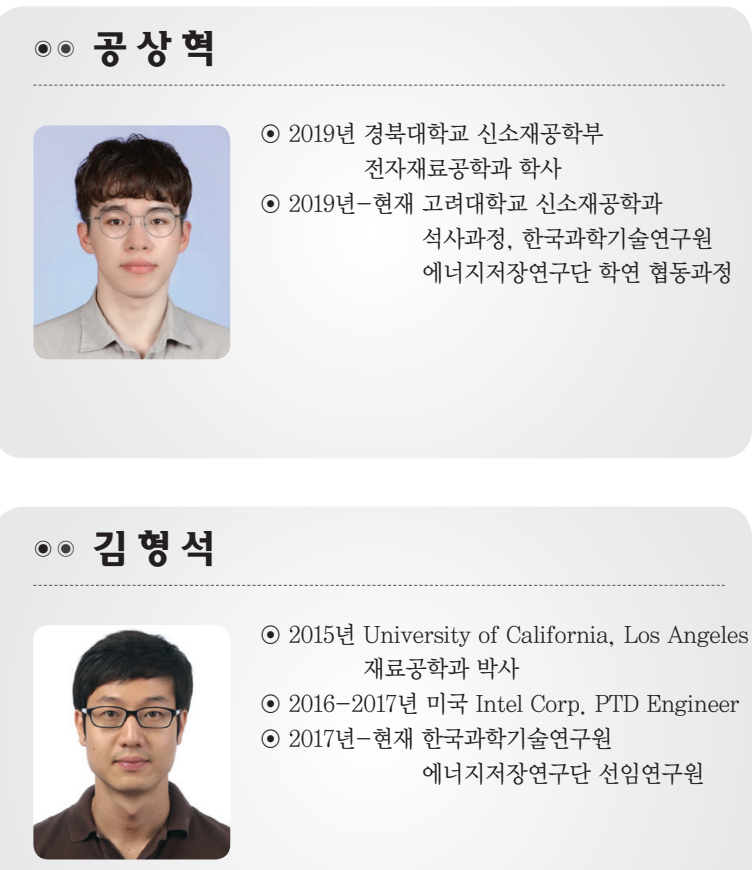

• 2015년 University of California, Los Angeles 재료공학과 박사

• 2016-2017년 미국 Intel Corp. PTD Engineer ๑ 2017년-현재 한국과학기술연구원 에너지저장연구단 선임연구원 